the St. George Hospital. The former showed only one case in ten years, and the latter only one in fifteen years. Martin ${ }^{2}$ says that the records of Johns Hopkins Hospital, together with those of the Union Protestant Infirmary in Baltimore, out of 280 cases of obstruction, show only one due to gall-stone. He also states that he was able to collect but four cases from the six leading surgeons of that city, and that two of the men with the largest and most active careers had never seen a case.

Access to the intestinal canal practically always presupposes the passage of the stone through a fistulous tract between the gall-bladder and the intestine. The point of communication is most commonly the duodenum, and occasionally the colon, but some very strange cases have been reported in which the stone escaped into the urinary bladder, or into the stomach, being later vomited. For obvious reasons the stone can very seldom produce obstruction when it enters the colon, but in the small intestine, because of the gradual narrowing of the lumen, "funnel-shaped" it has been called, the stone is usually arrested within a few feet of the ileo-cecal valve, sometimes in the valve itself.

Few cases of gall-stone ileus have been diagnosed prior to opening the abdomen. Barnard was able to make an accurate diagnosis in one of his three cases, but Møller ${ }^{3}$ of Copenhagen, in analyzing twenty-two cases of gallstone ileus in which he operated, commenting on diagnosis, says that "there had been no previous symptoms of cholelithiasis in quite a number of cases," while typical coljes had occurred in only six of the twenty-two. Other observers have made similar statements, so that we can obtain but little aid from this source.

Møller further noted that "even when the abdomen is opened, the diagnosis is difficult; in a number of instances the conditions first found were assumed to be sufficient to explain the ileus and no further search for a gall-stone was made, and thus it escaped detection. In only three cases was the ileus traced to its true cause before the operation. Only four of the twenty-two patients survived; the mortality was thus 82 per cent." In all of his cases, however, the obstruction had existed for two weeks or more before the operation.

The peculiarly fatal nature of this form of ileus is shown in the experience of all other writers on the subject, the mortality following operation, in the opinion of one operator, who lost twelve out of thirteen cases, being prohibitory. Even in the recent statistics collected by Martin, the death-rate is given as 69 per cent., the reasons for which he thinks are due to the advanced age of the patients, the fact that operation is often undertaken as a last resort, and the long-standing toxemia resulting from obstruction.

2. Martin: Ann. Surg., May, 1912.

3. Møller, P.: Gall-Stone Ileus, Hospitalstid., March 26, lvi, No. 13; abstr., The JourNal A.M.A., May 17, 1913, p. 1589.

Resuscitation.-An interesting and useful number of the medical series of publications of the University of Missouri is that on resuscitation, by $D$. H. Dolley. The author discusses at some length the scientific basis of resuscitation, the specialized work of the organs of the body, the viability of the brain and nervous system, which is the weakest point in respect to viability after asphyxiation, the viability of the other organs, clinical death and true death and instances of resuscitation after prolonged periods of apparent death. Methods of resuscitation and their relative efficiency are given consideration, and the treatment of accidental asphyxiation produced by different agents is set forth. It is suggested that too much reliance should not be placed on the popular "pul. mator" and similar contrivances.
SEVERE ERYTHEMA MULTIFORME WITH ANAPHYLAXIS DUE TO OYSTER PROTEIN

H. H. HAZEN, M.D.

Professor of Dermatology, Georgetown Lniversity, School of Medicine; Clinica! Professor of Dermatology, Howard

University, School of Medicine

WASHINGTON, D. C.

Erythema multiforme with visceral manifestations of varying degrees of severity is recognized by the majority of clinicians. The descriptions of Osler" still stand as classics; but little has been added to them.

'The etiology of the condition has never been settled, except that the majority of observers are agreed that there is a toxemia of some kind, whatever that may mean. Köbner ${ }^{2}$ thought that it was angioneurosis due to vasomotor disturbances; Lewin ${ }^{3}$ that reflex causes, especially those of urethral origin, might be responsible. Galloway ${ }^{4}$ considered that auto-intoxication was to blame, and Finger ${ }^{5}$ thought that the local effects of bacteria on the tissues might be the cause. Certain other observers ${ }^{6}$ have shown its association with typhoid fever, or with other infections. Corlett ${ }^{7}$ has definitely established that some cases may be due to streptococcus infections.

In a recent case, under my care, the patient apparently suffered because of a definite anaphylaxis against oyster protein, and because of this fact the case is worthy of being put on record.

E. F., white woman, aged 50 , trained nurse, was referred to me, Jan. 3, 1913, by Dr. Jackson of Washington, because of a very severe attack of hives.

The history showed that about the middle of December she had eaten a few raw oysters, and that a few hours later had had a rather violent attack of urticaria that lasted about seventy-two hours. Accompanying this attack there had been some fever and fairly definite abdominal pain.

On the night of December 31 she had eaten about half a dozen fried oysters, and four hours later was seized with abdominal pain and very severe urticaria, which was not relieved by cathartics and simple lotions.

When seen by me, January 3 , her entire body was covered by an eruption that was a combination of the macular type of erythema multiforme and of urticaria. None of the lesions were more than $2 \mathrm{~cm}$. in diameter, and many were distinct wheals, but the macular lesions persisted for several weeks, and were not at all wheal-like. The itching was very intense, and the skin was covered by scratch marks. The temperature by mouth was 10l, and the pulse 104. The right knee and the left elbow were swollen and painful, and the movement in them was markedly restrieted. The abdomen was slightly tender, especially over the left upper quadrant. The urine had a specific gravity of 1.010 , and contained no albumin or sugar, no casts, red or white blood-cells, and no excess of indican. The hemoglobin was 90 per cent., and the white cells numbered 16,500. A differential count of 500 leukscytes stained by the Jenner method showed the polymorphonuclears 45 per cent., eosinophils 17.8 per cent., large mononuclears 1 per cent., small mononuclears 32 per cent., transitionals 4.2 per cent. and mast-cells 0.8 per cent.

January 8 it was noted that the cutaneous condition was no better, in spite of the usual treatments, and that the tem-

1. Osler: Am. Jour. Med. Sc., 1895 , cx, 629 ; ibid., 1904, cxxvil, 1 ; Brit. Jour. Dermat., 1900 , xii, 227. $186 \stackrel{2}{4}$.

3. Lewin: Berl. klin. Wchnschr., 18.76, xiii, 321

4. Galloway : Brit. Jour. Dermat., 1903, xv, 235.

6. Parker and Hazen: Bull. Johns Hopkins Hosp., 1911, xxii. $7 \boldsymbol{9}$.

Forlett : Jour Cutan. Dis., 1908, xxri, 7 
perature was 104.5 by mouth. Abdominal pain had been so severe as to simulate gall-stone colic, but the tenderness was on the other side of the abdomen, and there was no jaundice. The tongue was heavily coated but otherwise the mucous membranes were clear. Both knees and both elbows were now involved. There had been slight bleeding from the nose, and a touch of bronchitis of the large tubes. The leukocytes numbered 12,000 , but the eosinophils were 20 per cent. Hexamethylenamin was tried in large doses.

January 10 the temperature was 101 , and the joint and abdominal symptoms were better, but the rash had not changed and still itched as intensely as ever.

January 20 the abdominal pain was gone and there was only an occasional attack. The temperature was normal, and the patient looked much better, but the cutaneous manifestations were practically no better. 'i he patient was given 50 million dead colon bacilli and 200 million dead Staphylococci albi.

On the 30th it was noted that the patient became better after the injection of vaccine, but that for the last two days she had been worse again so far as the cutaneous eruption was concerned. She was given 75 million colon bacilli.

February 5 she was very much better, and was given 100 million colon bacteria. The patient's convalescence was uninterrupted.

On account of the definite history of the eruption following the eating of oysters, especially when the previous indulgence in the same article of diet had excited an outbreak, it was determinel to prepare a vaccine from an oyster, and inject some of it just beneath the skin, as is done in the luetin test, to see if there would be a local skin reaction, such as has been obtained in cases of fagopyrism, or buckwheat poisoning. ${ }^{8}$ Accordingly Dr. VanSwearingen, pathologist to Freedmen's Hospital, prepared me a fine emulsion from an oyster, heated it at $60 \mathrm{C}$. for one hour, and placed it in a sterile bottle. An injection of 5 minims was made just beneath the skin on February 15. No local reaction followed, but within three hours the temperature had risen to 102 , the pulse-rate to 115 , and there was a violent attack of urticaria, that lasted two days. Accompanying this there was general malaise, sone nausea, and slight abdominal pain. In two days, however, these symptoms disappeared, and up to the present time she has remained well.

'The attack of urticaria, with visceral manifestations, excited by the injection of the oyster vaccine, although other hypodermics had not caused an exacerbation of the symptoms, would seem to show that the oyster proteins had caused a condition of hypersusceptibility, and that the attack of December 30 as well as the attack experimentally excited on Februarv 15 were anaphylactic phenomena.

The Rochambeau.

\section{VOMITING OF PREGNANCY TREATED BY INJEC TION OF BLOOD OF NORMAL PREGNANT WOMEN}

\section{Arthur H. Curtis, M.D. Chicago}

The following case is reported because of the outcome of the treatment used and in the hope that others may be induced to employ the same method in suitable cases:

History. - The patient, aged 36, first seen during the sixth month of pregnancy, had previously undergone three labors. Eight years before I saw her the first child was delivered with forceps. This was followed by puerperal infection with pyemia, and ultimately by return to fairly good health. A second pregnancy was interrupted because of placenta praevia; the third was normal in all respects and resulted in the normal birth of a full-term child, now four years of age. In none of these pregnancies were there evidences of intoxication or renal disturbance. A moderate amount of nausea, almost unaccom-

8. Smith. Harry Lee: Bull. Johns Hopkins Hosp., 1909, xx, 153 ; Buckwheat-Poisoning, Arch. Int. Med., May, 1909, p. 350. panied by vomiting, occurred each time during the early months.

Fourth Pregnancy.--For three months the course had been regular. Then general malaise began, accompanied with irregular fever of from one to three degrees. With the onset of fetal movements, tenderness, dragging and aching pain in the right lower quadrant became a constant feature. Nausea developed and was followed by vomiting which became intractable. Repeated physical examinations and analyses of urine were negative. Various therapeutic measures proved unavailing. At the time of examination no physical abnormalities were evident. The patient was not neurotic despite incessant vomiting for a period of five weeks, with associated loss in weight and strength. She believed that all food was vomited, but fasting for twenty-four hours caused a marked accentuation of weakness, which indicated that some nourishment had been retained.

Treatment.-By means of a petrolatum-coated syringe, 15 c.c. of blood were withdrawn from a pregnant woman in whom the Wassermann reaction was negative, and were at once injected into the muscular tissues of the patient's back. Despite the fact that she felt no confidence whatever in the treatment, the symptoms improved within eighteen hours. Emesis continued, but a large proportion of food was retained. Five days later, from another pregnant woman in whom the Wassermann reaction proved negative, a considerable amount of blood was withdrawn, immediately defibrinated and 10 c.c. were injected into the patient, with the result that complete cessation of vomiting occurred within eighteen hours. Two subsequent injections of defibrinated blood were made within the next two days, after which all treatment was discontinued.

Pregnancy continued undisturbed and was followed by normal labor at term with birth of a healthy child.

909 Monroe Building.

Strangulated Hernia with Gangrene,-Fred D., aged 22, was attacked at 6 p. m., Nov. 22, 1913, with a sudrlen pain in the right testicle. The pain was not severe enough to prevent sleeping, but on arising in the morning the patient found the testicle swollen and painful. He felt so sick that he was advised to hurry to his home, 50 miles away, the physician telling him it was an orchitis and "would need lancing." There was no history of specific infection, traumatism or grip, but the patient declared that the swelling began in the testicle. On reaching home, he called his physician, Dr. MeDaniel, who made a diagnosis of orchitis (second day), but later on the doctor was not satisfied with the diagnosis owing to the violence of the patient's symptoms. The third day the patient began to vomit frequently; the abdomen was greatly distended, but not very tender, pulse 98 and temperature 99.8; he was restless and had a very anxious facial expression. The scrotum was as large as a cocoanut; the skin was bluish black and the prepuce the same. Both began sloughing the morning of the fourth day. I saw the patient at $11 \mathrm{p}$. m., end of fourth day, and found all the above-described conditions present but more pronounced. The scrotum was black and sloughing; also the skin of the right side of the penis and the prepuce were in the same condition. There was a foul odor from the blackish exudate. We suspected strangulated hernia, but never having seen such a condition of the scrotum and penis in any strangulated hernia, I was not sure what we had to deal with. The operation revealed a large loop of small bowel in the scrotum, which was black and gangrenous and of a very offensive odor. I made a resection of 9 inches of the small bowel, using a medium-sized Murphy button, and did the best Bassini operation I could under the circumstances. The anesthetist, Dr. Bowden, reported the patient dying on the table, but nevertheless the operation was completed. Just as I finished, the patient "flinched" and I found that he was not so dead as we had thought. He finally rallied, and has made a good recovery. He passed the button the eleventh day.-L. P. Allison, M.D., Brownwood, Tex. 